\title{
A Multidisciplinary Design Optimization Tool for Spacecraft Equipment Layout Conception
}

\author{
Valentino Lau1, Fabiano Luis de Sousa ${ }^{1}$, Roberto Luiz Galski , Evandro Marconi Rocco', \\ José Carlos Becceneri ${ }^{1}$, Walter Abrahão dos Santos ${ }^{1}$, Sandra Aparecida Sandri
}

\begin{abstract}
One issue the design team has to face in the process of building a new spacecraft, is to define its mechanical and electrical architecture. The choice of where to place the spacecraft's electronic equipment is a complex task, since it involves simultaneously many factors, such as the spacecraft's required position of center of mass, moments of inertia, equipment heat dissipation, integration and servicing issues, among others. Since this is a multidisciplinary task, the early positioning of the spacecraft's equipment is usually done "manually" by a group of system engineers, heavily based on their experience. It is an interactive process that takes time and hence, as soon as a feasible design is found, it becomes the baseline. This precludes a broader exploration of the design space, which may lead to a suboptimal solution, or worse to a design that will have to be modified later. Recently, it has been shown the potential benefits of automating the process of spacecraft's equipment layout using optimization techniques. In this paper, a prototype of an Excel ${ }^{\circledR}$ based tool for multidisciplinary spacecraft equipment layout conception is described. Provided the geometric dimensions, mass and heat dissipation of the equipment, and the available positioning area, the tool can automatically generate many possible trade-off solutions for the layout. It allows the user to set specific equipment to specific areas of positioning, and different combinations of objective functions can be used to drive the design. The features of the tool are shown in a simplified three dimensional problem.
\end{abstract}

KEYWORDS: Layout optimization, Spacecraft, Conceptual design, Electronic equipment.

\section{INTRODUCTION}

In the conceptual phase of the development of a new spacecraft, different candidate solutions for its electrical and mechanical architectures are assessed, in a search for one which would fit the spacecraft mission, within the constraints of cost and schedule. It is in this phase that the main features of its subsystems are defined, and where the systemic and multidisciplinary character of the design process becomes more relevant to the definition of its cost and performance.

The assessment of different solutions for the mechanical and electrical architecture includes the positioning of the spacecraft's equipment over its structure panels, aiming at satisfying mechanical and electrical requirements or constraints. A target position for the system's mass center, preference of moment of inertia in a given direction, minimization of electromagnetic interference, avoidance of high heat dissipation due to equipment being positioned close to another, and minimization of cabling are examples of such concerns. The early positioning of the spacecraft's equipment is usually done "manually" by a group of system engineers, heavily based on their experience. Coupled to an analysis stage, where the system's performance and constraints are verified, the spacecraft's equipment layout definition is an interactive process that takes time and hence, as soon as a good feasible design is found, it becomes the baseline. This reduces the exploration of the design space, and increases the probability that better designs are missed. Thus, increasing the creation of candidate solutions by numeric automatization of the 
search through the conceptual design space would increase the possibilities that better designs are found.

The works of Ferebbe Jr. and Powers (1987) and Ferebbe Jr. and Allen (1991) are probably the firsts to propose numerical optimization methods for automating the process of determining the layout of equipment during the conceptual phase of spacecraft design. In a series of works, Teng et al. (2001), Sun and Teng (2003), Zhang et al. (2008) and Teng et al. (2010), studied the efficacy of the approach when applied to a spinning telecommunication satellite, considering also the influence of the application of different optimization methods. These works have in common the focus on placing the equipment driven by the system's mass properties (position of mass center and magnitude and direction of principal axis of inertia) requirements, subject to geometric constraints. In Jackson and Norgard (2002), thermal issues and minimization of wiring between equipment were introduced as objectives to be considered in the search for candidate solutions in the design space. Thermal requirements are in fact one of the main drivers of the spacecraft layout design, and in the context of conceptual layout optimization they have been treated either by trying to meet requirements of equipment heat dissipation uniformity over the spacecraft's structural panels (Jackson and Norgard, 2002; Hengeveld et al., 2011) or target temperatures on them (De Sousa et al., 2007). In the later work the problem was treated as fully multi-objective, that is, opposed to the usual approach of transforming it in mono-objective before optimization is performed, a set of trade-off solutions is the objective of the search. This provides more information about the design space, leaving for a posteriori analysis the choice of which solution will be implemented.

Coupling optimization algorithms with Computer Aided Design (CAD) and engineering analysis packages, provides an efficient way to tackle the spacecraft equipment layout problem, as highlighted in the works of Baier and Pühlhofer (2003), Pühlhofer et al. (2004) and Cuco (2011). In the later one, a new methodology was proposed to address the problem. The Cuco's methodology (Cuco, 2011; Cuco et al., 2014) considers the main drivers commonly used to define the equipment layout during the spacecraft's conceptual design:

- The position of the system's center of mass;

- The alignment and strength of the system's main axis of inertia;

- Avoidance of concentration of high heat dissipation equipment over the satellite panels; and

- Equipment functional requirements.
The methodology of Cuco (2011), or different versions of it, may be implemented in different ways using commercial or custom made software. Cuco (2011) used modeFrontier ${ }^{\circledR}$ to couple Solidworks ${ }^{\circledR}$, Matlab $^{\circledR}$, Excel $^{\circledR}$ and an executable written in $\mathrm{C}$, for such purpose. The advantage of using a software such as modeFrontier ${ }^{\circledR}$ as the core tool to implement the methodology is that, since it was specially developed to tackle optimization problems and act as an integrator of other CAD or Computer Aided Engineering (CAE) tools, it has readily available on its internal features different optimization algorithms and techniques to be used on the problem, and provides a user-friendly interface to integrate other tools and analyze the results. On the other hand, the user has limited or no access to changes on the workings of these tools, what may affect his/her ability to explore new ways of addressing the problem. In the context of a research tool for the exploration of different concepts and algorithms to address the spacecraft equipment layout optimization problem, Excel ${ }^{\circledR}$ would provide a convenient alternative, since it can be used as a platform where new optimization algorithms can be embodied, as a calculator for engineering analysis, data storage, visualization of results, as well as an integrator of CAD and CAE tools. It also has the advantage of being known and be available largely in the engineering community.

In the present paper, an Excel $^{\circledR}$ based tool for spacecraft equipment layout is presented. Built using Cuco's (2011) methodology as the optimization framework, it can provide the spacecraft design team an efficient and easy way to explore the layout conceptual design space. Excel ${ }^{\circledR}$ was coupled to SolidWorks ${ }^{\circledR}$, which is used to calculate design parameters and as a graphical interface, where candidate layout configurations can be visualized. The tool's concept and early application tests were first presented in the 22th International Congress of Mechanical Engineering (COBEM 2013) (De Sousa et al., 2013). The present paper is an updated version of the former. It introduces new features such as integrated decision making criteria for selection of solutions on the approximate Pareto frontier, additional objective functions and three-dimensional (3D) capability.

In the Sections that follow, the general spacecraft equipment layout optimization problem is formulated, a prototype of the layout tool is presented and a simplified $3 \mathrm{D}$ example of application is shown. 


\section{SPACECRAFT EQUIPMENT LAYOUT PUT AS AN OPTIMIZATION PROBLEM}

The spacecraft's layout problem can be tackled as a multidisciplinary multiobjective optimization problem and can be generally stated as:

Minimize

$f_{\mathrm{i}}(\mathrm{x}) ; \mathrm{i}=1$ to $\mathrm{I}$

Subject to:

$g_{\mathrm{k}}(x) \leq 0 ; \mathrm{k}=1$ to $\mathrm{K}$,

$h_{1}(x)=0 ; 1=1$ to $\mathrm{L}$

$x_{\text {jmin }} \leq x_{\mathrm{j}} \leq x_{\text {jmax }},, \mathrm{j}=1$ to $\mathrm{J}$

where $f_{\mathrm{i}}$ is a vector of I objective functions, $x_{\mathrm{j}}$ is a vector of $\mathrm{J}$ design variables, $g_{k}$ and $h_{1}$ are vectors of $K$ and $L$ inequality and equality constraints, respectively, and $x_{\text {jmin }}$ and $x_{\text {jmax }}$ are the bottom and upper boundary constraints on the design variables.

The objective functions encode the design requirements for the spacecraft, such as a target position for its mass center, whereas the constraints define the viable design space. For example, there must be no mechanical interference among the equipment. In the simplified case study showed further in the text these points will be made clear.

The approach for the spacecraft equipment layout problem proposed by Cuco (2011) is used as the general framework to build the tool presented herein. The design variables are defined considering the faces of the panels where the equipment would be positioned and, over a given panel face, the local coordinate position of the equipment mass center being positioned on that panel. For a box-shaped equipment, the angle formed between the box edge and the panel axis is also a design variable. Hence, each equipment has 4 design variables: one index indicating in which panel's face it is allocated, two local coordinates $\mathrm{x}$ and $\mathrm{y}$ of the position of the center of mass projected on the panel, and one orientation angle. For example, if there are 8 box-shaped equipment to be positioned and 2 panels available for positioning, there are 32 design variables for optimization. Design requirements for the position of the system's mass center, grouping of sets of equipment, avoidance of "hot spots" over the panels and, the alignment of the principal axis of inertia and the proportion of the principal moments of inertia are tackled by five objective functions, while geometric and functional requirements are take into account as constraints. In Cuco's methodology, the result of the optimization is a set of candidate non-dominated solutions for the layout and its respective approximate Pareto frontier. The decision of which solution, or solutions, would be subject to a further analysis to become the baseline layout is left for the engineering team responsible for the layout design. The Cuco's methodology framework embodies the basic aspects to be considered by any computational environment aimed at providing the system's engineering team, a tool for the spacecraft's equipment layout, during its conceptual design phase. It is flexible enough to accommodate design goals being treated either as objective functions or constraints.

Adding to Cuco's work, the tool presented herein also incorporates decision making criteria to help the design team choose one or more candidate solutions for further evaluation, after the approximates Pareto set and Pareto frontier are returned.

For the general three-dimensional spacecraft layout problem, a practical tool must allow the exploration of any combination of equipment and positioning panel, as well as the possibility for the user to set a specific combination of equipment/panel. For example, it may be desirable that some equipment is positioned over a panel of the spacecraft with the least incidence of Solar thermal radiation. Moreover, functional aspects may require that some equipment is fixed in a given position, or that a set of them are positioned close to each other. All these features are implemented in the tool presented here.

The main aspects considered for the conceptual spacecraft equipment layout are taken into account in the tool by 5 objective functions, which may be activated by the user independently. Mechanical interference between equipment is taken into account by constraints penalizing the objective functions, while parameterization of the design variables assures that the equipment remains inside the available positioning areas. The general optimization framework used for development of the tool is presented in Fig. 1.

In the present version of the layout tool, the multi-objective optimization problem was posed as: 


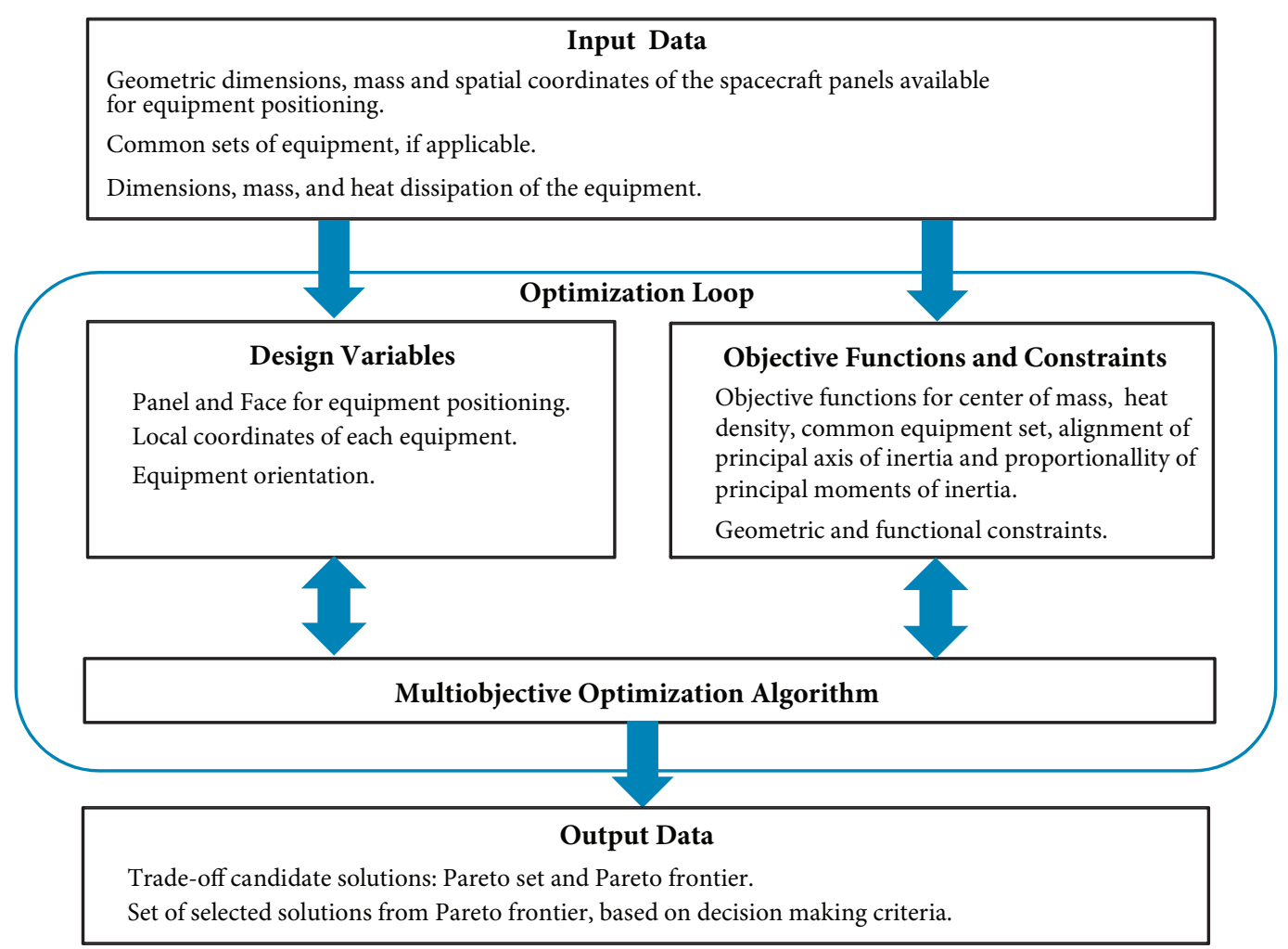

Figure 1. General optimization framework for the spacecraft equipment layout tool.

$$
\begin{aligned}
& \text { Minimize: } \\
& f_{1}=\sqrt{\sum_{i=1}^{3} \lambda_{i} \cdot\left(x_{i_{-} C M_{-} s i s}-x_{i_{-} C M_{-} t \arg e t}\right)^{2}} \\
& f_{2}=f_{2}^{\text {Global }}+\frac{r_{\min }^{2}}{A_{\text {Total }}} \cdot \sum_{p=1}^{\text {Npanel }} f_{2, p}^{\text {Local }} \\
& f_{2}^{\text {Global }}=\sqrt{\frac{\sum_{p=1}^{N_{\text {panel }}\left(\sum_{i=1}^{N_{\text {equi, }}} \frac{P_{i}}{A_{p}}-\frac{P_{\text {Total }}}{A_{\text {Total }}}\right)^{2}}}{N_{\text {panel }}}}
\end{aligned}
$$

$$
f_{5}=\frac{\left\|\vec{v}_{\text {inertia }} \times \vec{v}_{\text {targ } e t}\right\|}{\left\|\vec{v}_{\text {inertia }}\right\| \cdot\left\|\vec{v}_{t \text { arg } e t}\right\|}
$$

$$
f_{4}=\sqrt{\sum_{i=1}^{3} \rho_{i} \cdot\left(\alpha_{i}-\alpha_{i_{-} t \arg e t}\right)^{2}}
$$

Subject to:

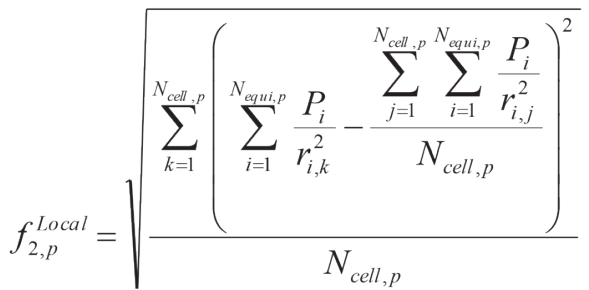

$$
\begin{aligned}
& I_{i}^{\text {face }} \in\left[1,2, \ldots, N_{\text {face }, i}\right] \\
& 0 \leq s_{i, 1}, S_{i, 2} \leq 1 \\
& I_{i}^{\theta} \in\left[1,2, \ldots, N_{\text {division } i}\right] \\
& V_{\text {inter }}=0
\end{aligned}
$$


$f_{1}$ represents the goal of having the center of mass $(\mathrm{CM})$ of the system, $x_{i_{-}{ }_{C M} \text { sys }}$, as close as possible to a given target center of mass, $x_{i_{-} \text {CM_target }}$. The parameters $\lambda_{i}$, which may assume zero or one value, are used to disable or enable the CM coordinate components. For example, if the CM longitudinal component of an spacecraft is less constrained than the other components, then only the lateral components could be enabled to drive optimization.

$f_{2}$ is an object function devised to approximate the heat density over the spacecraft's panels. This objective function is composed of two components. The first one, $f_{2}^{\text {Global }}$, measures how far the layout is from an ideal condition of uniformly heat distribution over the entire spacecraft. $N_{\text {panel }}$ is the number of panels; $N_{\text {equi,p }}$ is the number of equipment installed in panel $p$; $P_{\mathrm{i}}$ represents the heat dissipated by equipment $i ; A_{\mathrm{p}}$ is the projected area of panel p; $P_{\text {Total }}$ is the total heat dissipated; and $A_{\text {Total }}$ is the total projected areas of the panels. The second component, $f_{2, \mathrm{p}}^{\text {Local }}$, evaluates the heat dissipated by the equipment installed in panel $\mathrm{p}$ over discrete regions of this panel. The panel is divided in $N_{\text {cell,p }}$ rectangular cells, each side of them with the size of $r_{\min }$, which is the size of the smallest dimension, in contact with the panels, of all equipment divided by 2. $r_{\mathrm{i}, \mathrm{j}}$ is the distance between the center of the $i^{\text {th }}$ equipment to the center of $j^{\text {th }}$ cell, as seen in Fig. 2 .

Minimizing $f_{2, \mathrm{p}}^{\text {Local }}$ means that the standard deviation of the quantity $\sum_{i=1}^{N_{\text {omut }},} P_{i} / r_{i, j}^{2}$ is minimized, that is, the combined influence of all equipment over each panel cell would be the same.
This would avoid "hot spots" over the panel. The ratio $r_{\min }^{2} / A_{\text {Total }}$ is applied for scaling compatibility of these two components.

$f_{3}$ represents the goal of minimizing the distance between equipment belonging to the same common set. We define here a common set, as a group of equipment that should be positioned near each other. $d_{\mathrm{i}, \mathrm{j}, \mathrm{k}}$ is the Euclidian distance between the geometric centers of equipments $i$ and $j$ belonging to a common set $\mathrm{k}, N_{\text {equi,k }}$ is the number of equipment in common set $\mathrm{k}$ and $N_{\text {set }}$ is the number of common sets.

$f_{4}$ measures the alignment of the principal axis of inertia to the spacecraft global coordinate system; $\alpha_{i}$ are the angles formed between the $i$-axis of the principal inertia and global coordinate systems, as shown in Fig. 3; and $\alpha_{\mathrm{i}_{\text {target }}}$ is a given target angle. Analogously to $\lambda_{\mathrm{i}}$ in $f_{1}$, the parameters $\rho_{\mathrm{i}}$, which are set to zero or one, are used to disable or enable angle components.

The goal of $f_{5}$ is to achieve a given proportionality between the principal moments of inertia. $v_{\text {inertia }}$ is a vector which components are the tree principal moments of inertia, and $v_{\text {target }}$ is a given target vector, which components are positive values, that keep a desired proportion. For example, in a spacecraft controlled by spin, the longitudinal moment of inertia should be larger than lateral ones, say $n$ times, while lateral moments of inertia could be of the same order. Setting the longitudinal component of $v_{\text {target }}$ to $\mathrm{n}$ and the lateral components to 1 would represent this proportion. The vector norm of the cross product gives the area of the parallelogram formed by these two vectors. If they

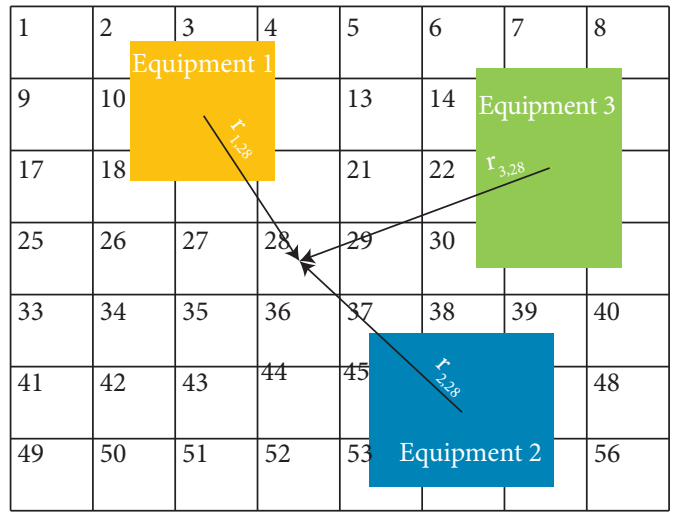

Figure 2. Representation of how the distance between the equipment and the panel's cells is considered in the heuristic used to calculate $\int_{2}^{\text {Local }}$. Example with three equipment and 56 cells. Only distances for cell 28 are shown in the example, but all cells are considered when calculating the value of $\int_{2}^{\text {Local }}$.

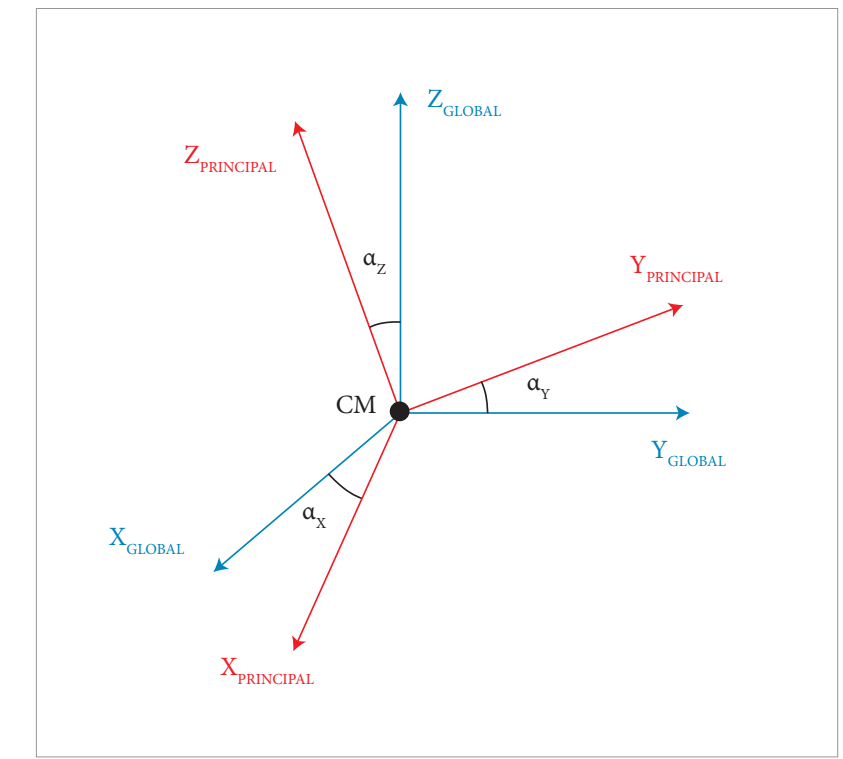

Figure 3. Angles between principal axis of inertia and global axis. 
are aligned, what means that $v_{\text {inertia }}$ has the same proportion of $v_{\text {target }}$, this area vanishes. On the other hand, if they are not aligned, a positive value is obtained. Normalization is used in order to keep $f_{5}$ in the range of $[0,1]$.

$T_{\mathrm{i}}^{\text {face }}, s_{\mathrm{i}, 1}, s_{\mathrm{i}, 2}$ and $I_{\mathrm{i}}^{\theta}$ are the design variables.

The first defines the panel and the face where equipment $\mathrm{i}$ is installed. This is an integer variable corresponding to the index of an element in a list that contains all available panel faces, coded as the panel ID number with a signal, positive for top face and negative for bottom face. The number of available faces, $N_{\text {face,i }}$, can vary for each equipment $i$, since constraints may be applied to restrict equipment installation.

The next two variables define the parameterized position of the geometric center of an equipment i over the panel. $B, L$ and $H$ are the equipment dimensions, while $L_{1}$ and $L_{2}$ are the panel dimensions, and $\theta$ is the equipment rotation angle, as shown in Fig. 4. The distances $e_{1}$ and $e_{2}$ are defined in Eq.14, and the relationship between the parameterized variables and the local coordinates $D_{1}$ and $D_{2}$ are presented in Eq.15. The values of the parametric variables $s_{i, 1}$ and $s_{i, 2}$ can vary in the range $[0,1]$. This parameterization guaranties that the boundaries of the equipment always lies inside the area of the panel.

$$
\begin{aligned}
& e_{1}=B \cdot\|\cos \theta\|+L \cdot\|\sin \theta\| ; \quad e_{2}=B \cdot\|\sin \theta\|+L \cdot\|\cos \theta\| \\
& D_{1}=\frac{e_{1}}{2}+s_{1, i} \cdot\left(L_{1}-e_{1}\right) ; \quad D_{2}=\frac{e_{2}}{2}+S_{2, i} \cdot\left(L_{2}-e_{2}\right)
\end{aligned}
$$

$I_{i}^{\theta}$ is an integer variable used to evaluate the rotation angle $\theta$ as indicated in Eq.16. The number of increments $N_{\text {division, } \mathrm{i}}$ is defined by the user. The angle $\theta$ varies in the range $0^{\circ} \leq \theta \leq 180^{\circ}$.

$\theta=\frac{\left(I_{\mathrm{i}}^{\Theta}-1\right)}{N_{\text {division, } \mathrm{i}}} \times 180^{\circ}$

$V_{\text {inter }}$ is the total volume of mechanical interference among equipment and structure. The equality constraint (Eq. 13) is treated as a penalty for the objective functions when it is violated, using an exterior penalty method (Vanderplaats, 2007) approach.

\section{DESCRIPTION OF THE SPACECRAFT EQUIPMENT LAYOUT CONCEPTUAL DESIGN TOOL}

The main components of the optimal layout tool are presented in Fig. 5.

The Excel workbook consists of 7 worksheets and 3 main macros. From the Read Me worksheet, a description of all parameters used in this tool is presented. In the Control worksheet, parameters used to define and activate
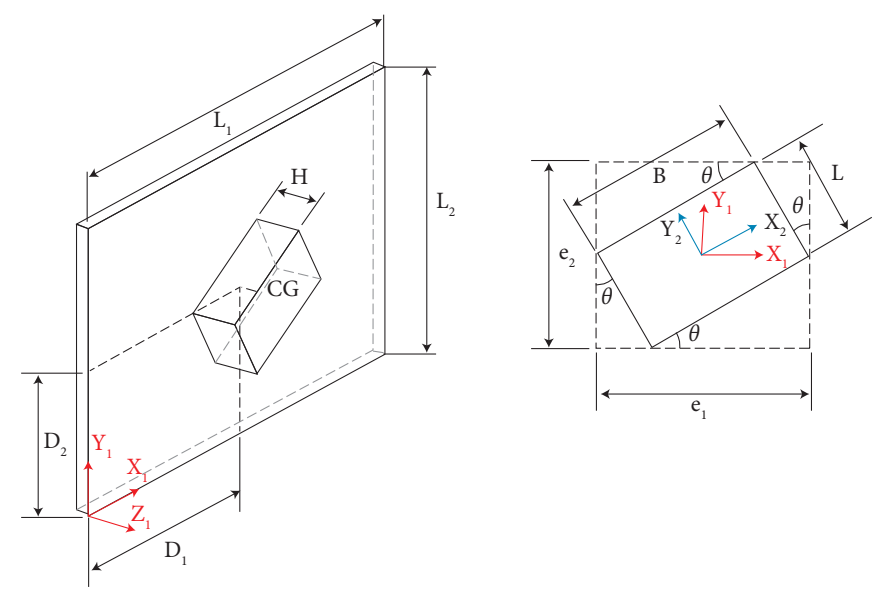

Figure 4. Equipment position over the panel. 
objective functions and constraints are entered. A specific geometric configuration, defined in the Panels and Equipment worksheets, is built in SolidWorks ${ }^{\circledR}$, which is launched by clicking a macro button inside the Control worksheet. All design parameters calculated inside SolidWorks ${ }^{\circledR}$, are returned to the Control worksheet. In the Panels worksheet the geometric characteristics of each panel available for equipment positioning is entered. In the present version of the layout tool only rectangular panels are modeled. In the Equipment worksheet, the mechanical and thermal characteristics of the equipment are entered, together with the information of what subsystem they belong. In the current version of the layout tool, rectangular, cylinder and sphere solid shapes can be used to simulate the equipment. The solids may be assigned with different colors. In this worksheet, it can also be entered values for the design variables. In the Problem Description worksheet, a brief description of the objective functions, constraints and design variables being considered in the optimization problem is provided. In the Choice of Optimizer worksheet, the optimization algorithm to be used is chosen and information concerning its operational, such as parameters and stopping criteria, is entered. The optimization process is initialized from this worksheet, by clicking a macro button representing an available optimization algorithm. This calls a routine that embodies the algorithm and links it to other routines that launch and control SolidWorks ${ }^{\circledR}$. Finally, in the Results worksheet, the approximate Pareto set and Pareto frontier obtained during the search are presented. Different types of graphs available in $\operatorname{Excel}^{\circledR}$ may be used in order to show the approximate Pareto frontier. For example, for problems with three objective functions, bubble or surface graphs may be used. In Fig. 6, screen prints of the seven worksheets are presented for illustration purposes.

The macros for the optimization algorithms, objective functions and routines that link Excel ${ }^{\circledR}$ to SolidWorks ${ }^{\circledR}$ are built using the VBA editor, in a modular approach, such that new optimization algorithms or objective functions can be added or removed from the tool, as desired. In its present version, only a real coded implementation of the M-GEO optimization algorithm (Galski, 2006), was incorporated to the layout tool. In Fig. 7 screen prints of the VBA editor and the SolidWorks ${ }^{\circledR}$ environment are shown.

The layout optimization process embodied in the layout tool just described is fully automatic. That is, once the "button" linked to an optimization algorithm is clicked in the Choice of Optimizer worksheet (for example, Play M-GEO in Fig. 3), the information on the Panels and Equipment worksheets are accessed, SolidWorks ${ }^{\circledR}$ is launched and linked to Excel $^{\circledR}$, the optimization performed and the results sent to the Results worksheet. The graph that plots the approximate Pareto frontier is also automatically updated. After the approximate Pareto frontier is retrieved, a particular layout solution may be visualized in SolidWorks ${ }^{\circledR}$ by selecting a solution ID and clicking in a macro button available in Result worksheet.

The automatic selection of particular solutions from the approximate Pareto frontier, based on dedicated decision making criteria that will be described ahead, is also calculated and listed in the Result worksheet.

\begin{tabular}{|c|c|c|}
\hline $\begin{array}{l}\qquad \text { Excel }^{\otimes} \\
\text { Worksheets: } \\
\text { 1) Read Me } \\
\text { 2) Control } \\
\text { 3) Data Input for Panels } \\
\text { 4) Data Input fot Equipment } \\
\text { 5) Problem description } \\
\text { 6) Choice Optimizer } \\
\text { 7) Results }\end{array}$ & $\begin{array}{l}\text { Visual Basic } \\
\text { for } \\
\text { Applications } \\
\text { (VBA) }\end{array}$ & $\begin{array}{l}\quad \text { SolidWorks } \\
\text { Calculate layout's: } \\
\text { 1) Center of Mass } \\
\text { 2) Principal Moments of Inertia } \\
\text { 3) Principal Axis of Inertia } \\
\text { 4) Mechanical Interference Volume } \\
\text { Visualizations of Equipment Layout } \\
\text { Configuration }\end{array}$ \\
\hline
\end{tabular}

Figure 5. Main components of the spacecraft equipment layout tool. 
Lau, V., Sousa, F.L., Galski, R.L., Rocco, E.M., Becceneri, J.C., Santos, W.A. and Sandri, S.A.
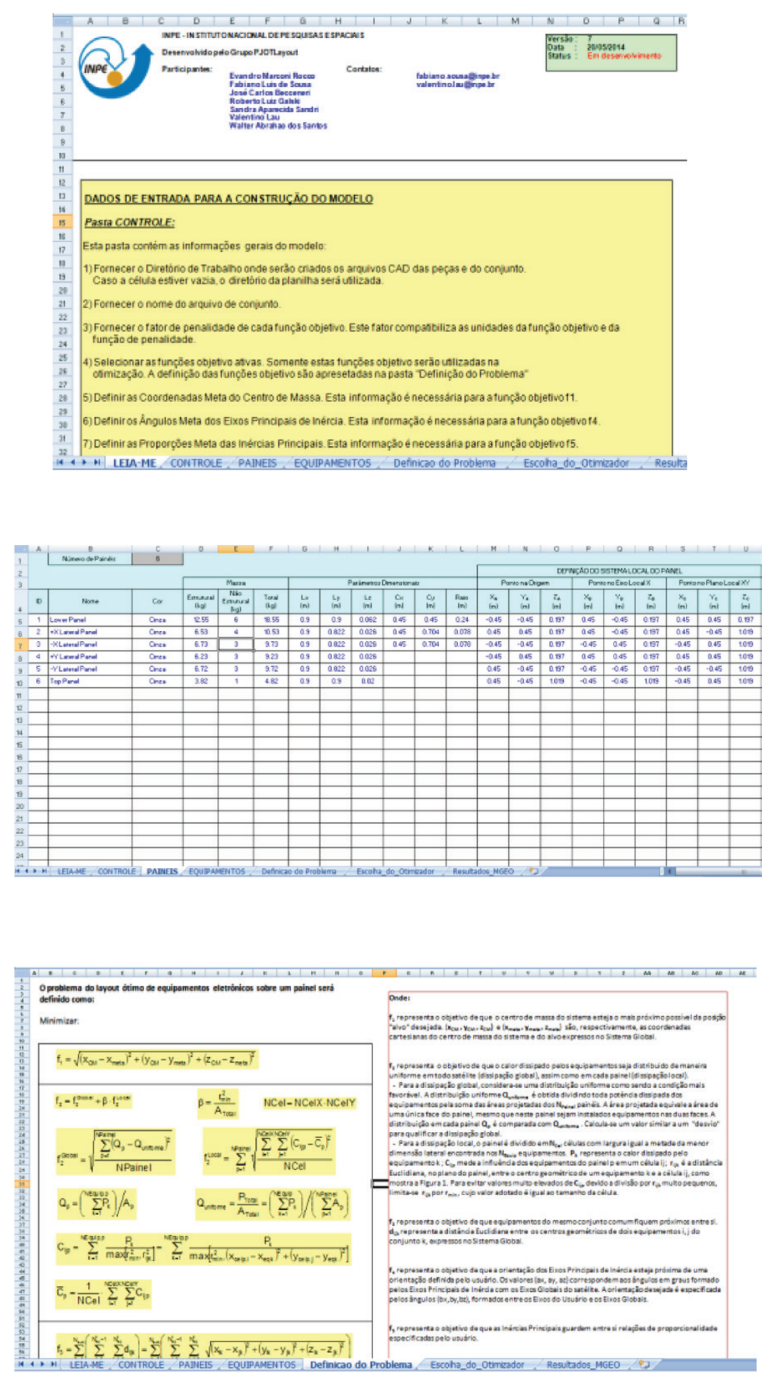
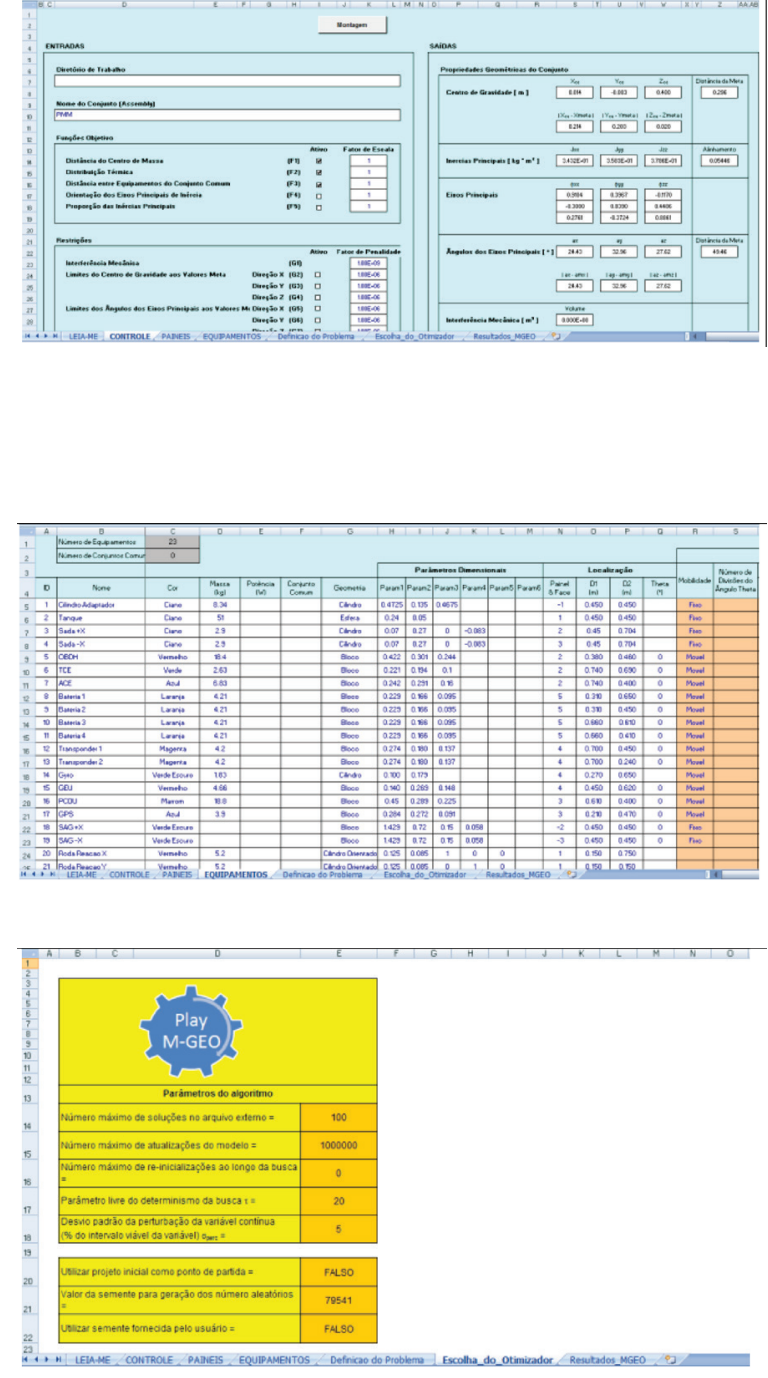

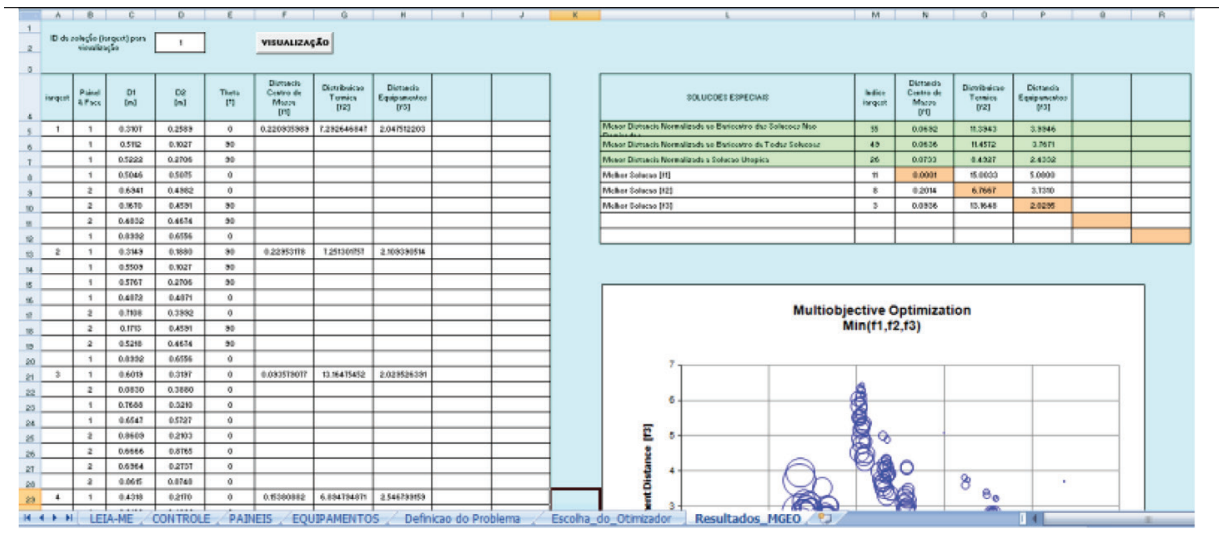

Figure 6. Screenshots of the layout tool Excel $^{\circledR}$ worksheets. 


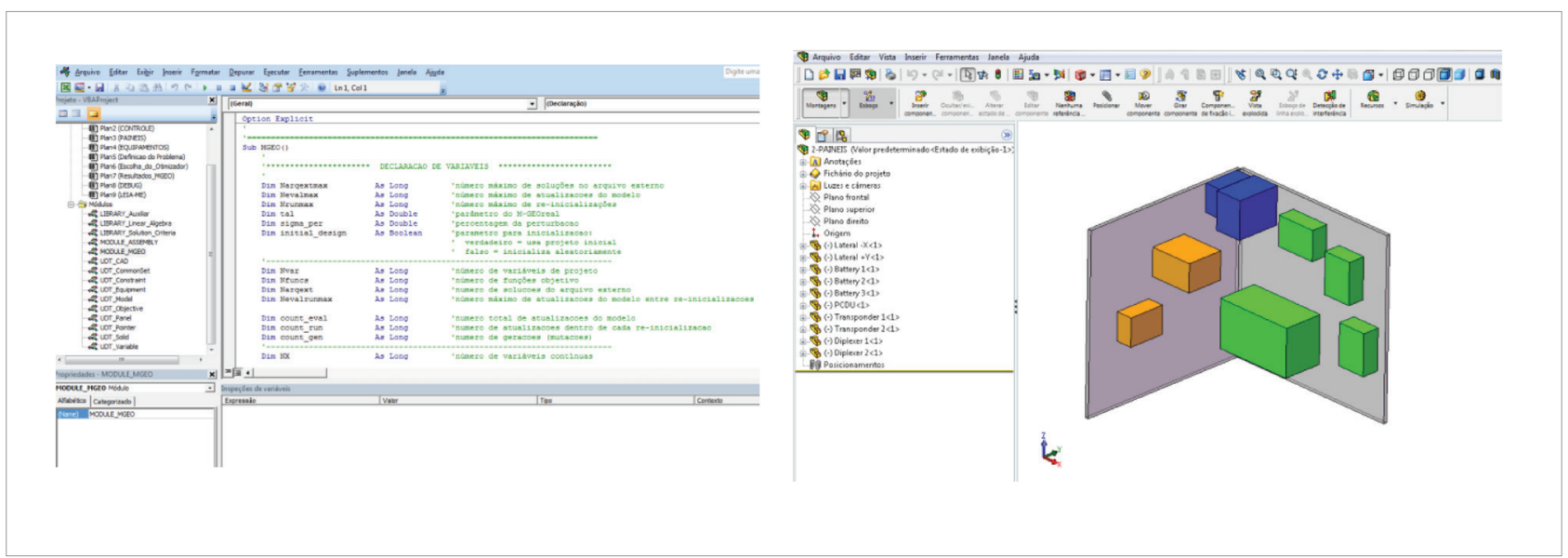

Figure 7. Screenshots of the VBA editor showing the M-GEO macro (left view) and SolidWorks ${ }^{\circledR}$ environment (right view).

\section{THE OPTIMIZATION TOOL}

The optimization algorithm implemented in the layout tool so far is based in M-GEO (Galski, 2006), a multiobjective version of GEO evolutionary algorithm (De Sousa et al., 2003; De Sousa, 2002). In an early version of the layout tool, the canonical M-GEO was used (De Sousa et al., 2013). As in the original GEO, in the canonical M-GEO the design variables are codified in binary strings. However, it has been shown that for problems where the design variables are continuous, a real coded GEO may perform better than its canonical version (Mainenti-Lopes et al., 2008), what was also verified with real coded versions of M-GEO (Mainenti-Lopes et al., 2012, Mainenti-Lopes, 2013). It has also been showed that GEO can work successfully treating discrete variables directly (De Sousa and Takahashi, 2005). Because in the spacecraft equipment layout problem there is a mix of discrete ( $I_{i}^{\text {face }}$ and $\left.I_{\mathrm{i}}^{\theta}\right)$ and continuous $\left(\mathrm{s}_{\mathrm{i}, 1}, \mathrm{~s}_{\mathrm{i}, 2}\right)$ design variables, was decided for the present version of the layout tool, to implement the M-GEO using the variables directly, instead of codifying them in binary strings. The main steps of the M-GEO algorithm as implemented in this work is described in Fig. 8.

Because the number of non-dominated solutions found during the optimization search can become very large, the user of the layout tool can set the maximum number of non-dominated solutions desired to be stored in the computer's memory and retrieved at the end of the search. Each time this number is exceeded, the "crowded distance" strategy proposed by (Deb et al., 2000) is used to select the point on the approximate Pareto frontier that is on its most crowded region, and it is removed from the solution set to be retrieved. For problems with a large number of non-dominated solutions, this approach helps the user to keep the approximate Pareto set within a size more manageable for decision making analysis, while keeping on the solution set representative solutions of the entire approximate Pareto frontier.

\section{SELECTING CANDIDATE SOLUTIONS ON THE APPROXIMATE PARETO FRONTIER}

Though a multiobjective problem may be considered formally solved when the approximate Pareto set is found, from the practical point of view it is not over, since at least one of the non-dominated solutions has still to be choose to be implemented, or further investigated. Hence, some decision making criteria were included in the layout tool to help the designer in choosing solutions on the approximate Pareto Frontier (PF). Following The Smallest Loss Criterion, defined by Rocco et al. (2003) and used by Venditti et al. (2010) and Rocco et al. (2013), the solutions on the approximate Pareto frontier closest to its barycenter, calculated either considering all solutions on the frontier or only its edge values, and the utopian solution (the coordinates on the objective space that represents the optimal solution of each objective isolated), are used as references to choose solutions on the PF, as shown in Fig. 9. Since the edge solutions on the PF are the best solutions for each objective function, they are also candidate solutions to be further examined. In a problem with two objective functions, such as the hypothetical one shown in Fig. 9, there may be up to 5 solutions on the PF chosen by the criteria just outlined. It must be pointed out that the final choice of which solutions would be subject of further analysis and eventual implementation is always up to the designer. Automatic decision making strategies, such as the ones described above, should be used to help the decision making process and not as a substitute for the decision maker. 
Step 1. Initialize randomly the population of I design variables (species) and calculate the values of the J objective functions. Update the file of non-dominated solutions.

Step 2. Calculate the values of the objective functions when, one at a time, the design variables are changed

$>$ (mutated). With a random uniform pertubation for the discret variable and, for the continuous ones, with a Gaussian pertubation with zero mean and standard deviation $\sigma_{\text {per }}$ equal to a given percentage of the variable's design interval. Update the file of non-dominated solutions.

Step 3. Choose randomly one of the objective functions and set it as the reference.

$\checkmark$

Step 4. For each design variable $i$ attribute a "change fitness" $\mathrm{CF}_{i}$ value equal to the value of the reference objective function choosen in Step 3, when the variable $i$ is changed as in step 2. For minimization problems, sort of population of design variables in accordance to the value of $\mathrm{CF}$, such that the variable with least $\mathrm{CF}$ receives index $\mathrm{k}_{i}=1$, and the one with the highest, index $\mathrm{k}_{i}=\mathrm{I}$. For maximization problems the sorting is done conversally.

Step 5. Mutate one variable with probability $\mathrm{P}_{i} \approx \mathrm{k}_{i}-$
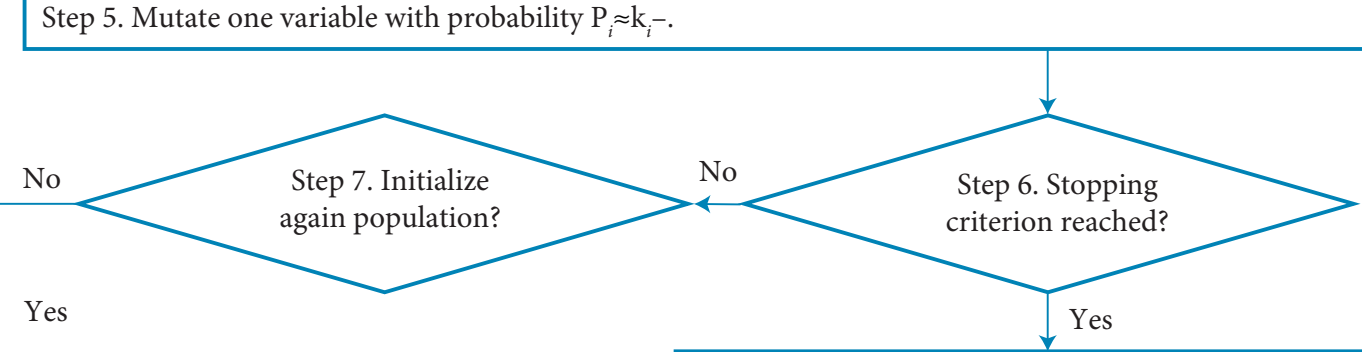

Step 8. return the Pareto set and Pareto frontier.

Figure 8. Main steps of M-GEO multiobjective optimization algorithm as implemented in this work.

\section{EXAMPLE OF APPLICATION}

A simplified three dimensional (3D) example is used for illustration of the tools features. It consists of placing 8 typical spacecraft equipment belonging to three different "common sets", over two squared panels, each one with an area of 1 $\mathrm{m}^{2}$. Only the panels' top faces were selected as available for equipment installation. The equipment positions were defined using a total of 32 design variables. Optimization was performed using two different sets of objective functions. In the first run, the selected objective functions are the heat density $\left(f_{2}\right)$ and the common set distance $\left(f_{3}\right)$. In the second run, the same objective functions previously used are selected, and one additional objective function, the center of mass $\left(f_{1}\right)$, is included. The chosen target center of mass is located $0.3 \mathrm{~m}$ far from the panels' top faces, with a height of $0.5 \mathrm{~m}$ from the lower edge of these panels. Therefore, two approximate Pareto

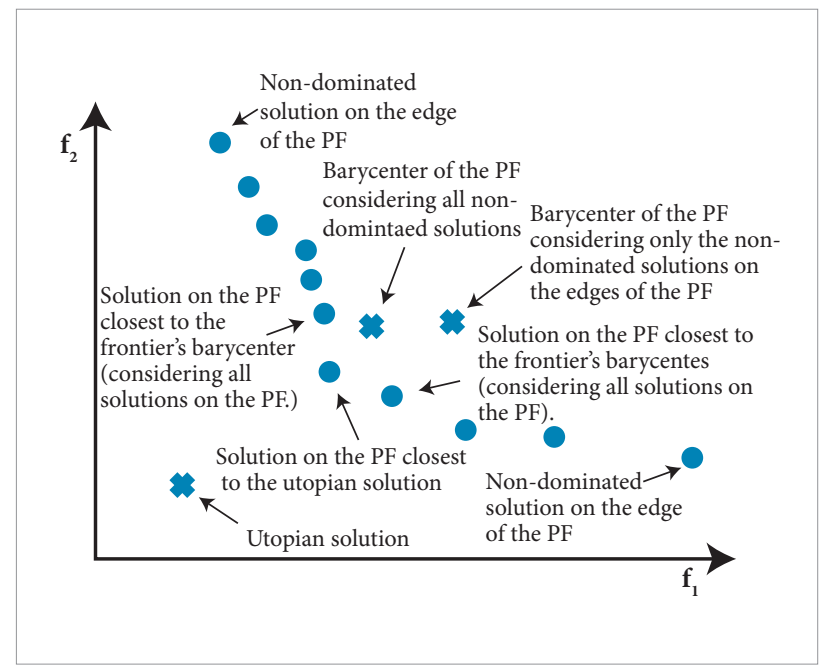

Figure 9. Some criteria to select solutions on the approximate Pareto Frontier (PF) for further analysis. A hypothetical example with two objective functions is presented here. Circles are non-dominated solutions. Crosses are reference marks based on the criteria (see text). 
frontiers are calculated, one with two objective functions and other with three objective functions.

\section{RESULTS OF SIMPLIFIED 3D CASE STUDY}

The values used for the geometric dimensions, mass, heat dissipation and common set for each equipment is shown in Table 1.

The M-GEO algorithm was used for the optimizations, starting with initial configurations randomly generated. The number of model updates was selected as the stopping criterion. All the selected objective functions are evaluated in each model update. In both runs, a total of 500,000 model updates were evaluated, corresponding to 15,624 generations in M-GEO. The deterministic parameter $\tau$ was set to 20 , the variable standard perturbation parameter $\sigma_{\text {perc }}$ was set to $5 \%$, and 5 re-initializations were used during optimizations. The stored non-dominated solutions were limited to a maximum of 100 solutions.

In the first run, with two objective functions $\left(f_{2}, f_{3}\right), 89$ nondominated feasible solutions were recovered at the end of this search. The obtained approximate Pareto frontier is shown in Fig. 10. The large number of non-dominated solutions makes evident the convenience of using decision making techniques to help the design team select candidate solutions for further analysis. Using the Smallest Loss criterion described above and the edge solutions, five non-dominated solutions were

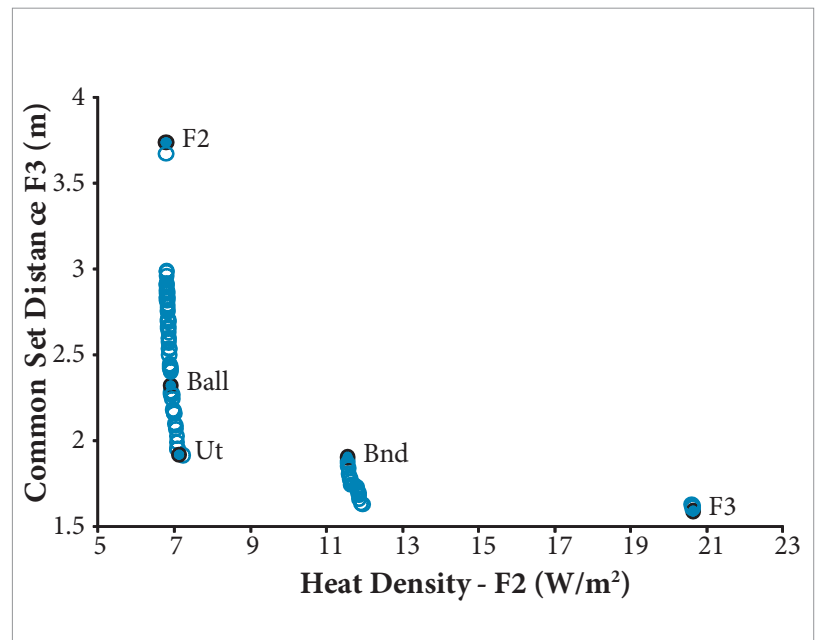

Figure 10. Optimization with two objective functions (F2, F3) Approximate Pareto frontier found using M-GEO.

Table 1. Geometric, mass, power and common set data of the equipment.

\begin{tabular}{|c|c|c|c|c|c|c|}
\hline \multirow{2}{*}{ Equipment } & \multirow{2}{*}{$\begin{array}{c}\text { Mass } \\
{[\mathrm{kg}]}\end{array}$} & \multirow{2}{*}{$\begin{array}{l}\text { Heat Dissipation } \\
\text { [W] }\end{array}$} & \multicolumn{3}{|c|}{ Dimensions } & \multirow{2}{*}{ Common Set } \\
\hline & & & $L X[m]$ & LY $(\mathrm{m})$ & $\mathrm{LZ}(\mathrm{m})$ & \\
\hline Battery 1 & 4.000 & 4.71 & 0.166 & 0.229 & 0.095 & 1 \\
\hline Battery 2 & 4.000 & 4.71 & 0.166 & 0.229 & 0.095 & 1 \\
\hline Battery 3 & 4.000 & 4.71 & 0.166 & 0.229 & 0.095 & 1 \\
\hline Diplexer 1 & 0.750 & 1.30 & 0.156 & 0.21 & 0.025 & 2 \\
\hline Diplexer 2 & 0.750 & 1.30 & 0.156 & 0.21 & 0.025 & 3 \\
\hline PCDU & 18.800 & 44.43 & 0.45 & 0.265 & 0.225 & 1 \\
\hline Transponder 1 & 2.800 & 29.20 & 0.156 & 0.21 & 0.094 & 2 \\
\hline Transponder 2 & 2.800 & 29.20 & 0.156 & 0.21 & 0.094 & 3 \\
\hline
\end{tabular}

Table 2. Optimization using two objective functions - Selected solutions on the approximate Pareto frontier.

\begin{tabular}{|c|c|c|c|c|}
\hline \multicolumn{2}{|l|}{ Selection Criterion } & $\begin{array}{l}\text { Index of solution on the } \\
\text { approximate Pareto frontier }\end{array}$ & $\begin{array}{c}f_{2} \\
{\left[W / m^{2}\right]}\end{array}$ & $\begin{array}{c}f_{3} \\
{[m]}\end{array}$ \\
\hline $\begin{array}{l}\text { Best value obtained for the thermal uniformity }\left(f_{2}\right) \\
\text { objective function. }\end{array}$ & $\mathrm{F}_{2}$ & 24 & 6.7826 & 3.7427 \\
\hline $\begin{array}{l}\text { Best value obtained for the distance between equipment of } \\
\text { the same common set }\left(f_{3}\right) \text { objective function. }\end{array}$ & $\mathrm{F}_{3}$ & 6 & 20.6329 & 1.5931 \\
\hline $\begin{array}{l}\text { Non-dominated solution closest to the barycenter } \\
\text { calculated only considering the edges of the approximate } \\
\text { Pareto frontier. }\end{array}$ & $\mathrm{B}_{\mathrm{nd}}$ & 3 & 11.5459 & 1.9071 \\
\hline $\begin{array}{l}\text { Non-dominated solution closest to the barycenter obtained } \\
\text { considering all solutions on the approximate Pareto } \\
\text { frontier. }\end{array}$ & $\mathrm{B}_{\text {all }}$ & 74 & 6.9032 & 2.3249 \\
\hline Non-dominated solution closest to the utopian solution. & $\mathrm{U}_{\mathrm{t}}$ & 31 & 7.1172 & 1.9220 \\
\hline
\end{tabular}


picked from the frontier. They are presented in Table 2 and shown in Fig. 10.

In Fig. 11, colors were used to distinguish equipment of common sets: green for set 1 , blue to set 2, and orange for set 3 .

In the second run, with three objective functions $\left(f_{1}, f_{2}\right.$, $\left.f_{3}\right), 100$ non-dominated feasible solutions were recovered. Figure 12 shows a plot of all these solutions. A colored scale was used to represent the $\mathrm{f} 1$ objective function. Table 3 presents the six selected solutions and Fig. 13 shows their layout configurations.

The results shown on Figs. 10 and 12 shows clearly the capacity of the layout tool generate a great number of feasible non-dominated solutions for a 3D problem, starting from a completely random configuration. The two objective functions in the first optimization run are naturally competitive: the heat density $f_{2}$ drives the layout to a spread equipment configuration to avoid "hot" spots, while the common set distance $f_{3}$ drives
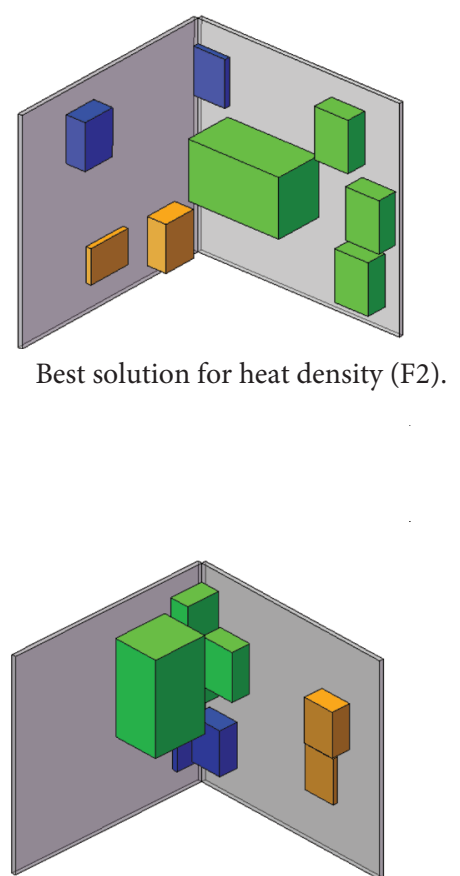

Solution closest to barycenter considering extreme solutions (Bnd)

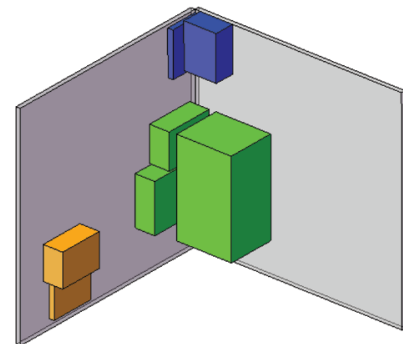

Best solution for equipment common set distance (F3)

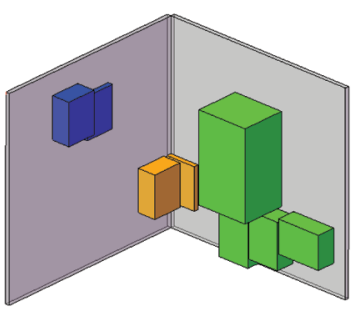

Solution closest to barycenter considering all solutions (Ball)

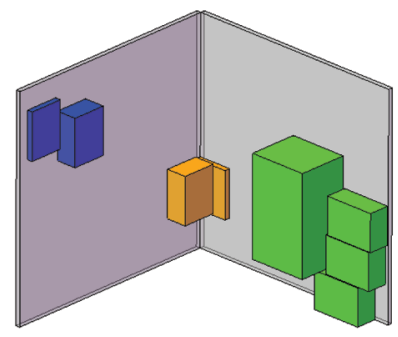

Solution closest to utopian solution (Ut).

Figure 11. Optimization with Two Objective Functions - Layout configurations for selected solutions. 
equipment to dense clusters in order to reduce the distances between equipment. Plotting the results with these two functions as coordinate axis highlights this competitive behavior. While the mass center objective function may not conflict with heat density and the equipment common set ones, it drives the search towards equipment configuration which mass center position is close to the desired one. Examining, in Figs. 11 and 13 , the solutions selected using the automatic decision making criteria, it can be seen clearly that the edge criteria generate very different layout solutions, due to the fact that they represent trade-off solutions that privileges one of the objective functions. On the other hand, the solutions chosen using the barycenter

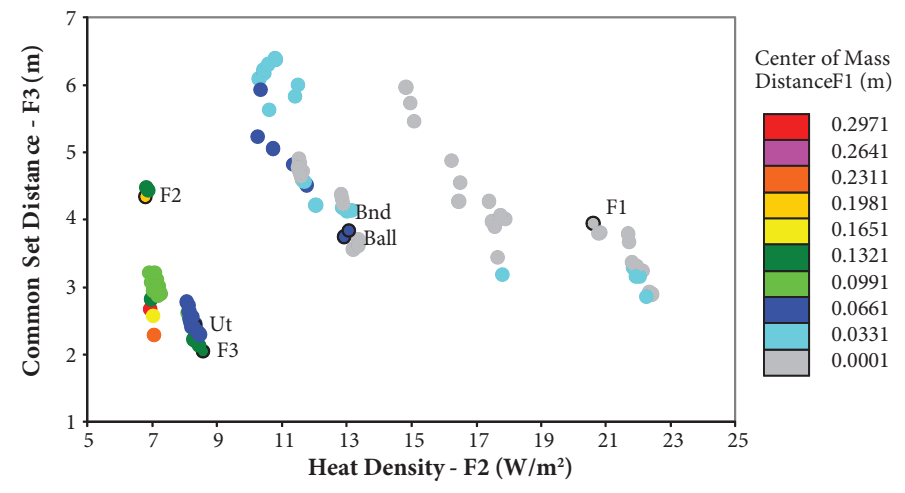

Figure 12. Optimization with Three Objective Functions - Approximate Pareto frontier found using M-GEO.

Table 3. Optimization with Three Objective Functions - Selected solutions on the approximate Pareto frontier

\begin{tabular}{|c|c|c|c|c|c|}
\hline Selection Criterion & & $\begin{array}{l}\text { Index of solution on the } \\
\text { approximate Pareto } \\
\text { frontier }\end{array}$ & $\begin{array}{c}f_{1} \\
{[m]}\end{array}$ & $\begin{array}{c}f_{2} \\
{\left[W / m^{2}\right]}\end{array}$ & $\begin{array}{c}f_{3} \\
{[m]}\end{array}$ \\
\hline $\begin{array}{l}\text { Best value obtained for the mass center }\left(f_{1}\right) \\
\text { objective function. }\end{array}$ & $\mathrm{F}_{1}$ & 5 & 0.0001 & 20.6003 & 3.9522 \\
\hline $\begin{array}{l}\text { Best value for the thermal uniformity }\left(f_{2}\right) \\
\text { objective function. }\end{array}$ & $\mathrm{F}_{2}$ & 16 & 0.1981 & 6.7834 & 4.3506 \\
\hline $\begin{array}{l}\text { Best value for the distance between equipment } \\
\text { of the same common set }\left(f_{3}\right) \text { objective } \\
\text { function. }\end{array}$ & $\mathrm{F}_{3}$ & 2 & 0.1457 & 8.5488 & 2.0540 \\
\hline $\begin{array}{l}\text { Non-dominated solution closest to the } \\
\text { barycenter calculated only considering the } \\
\text { edges of the approximate Pareto frontier. }\end{array}$ & $\mathrm{B}_{\mathrm{nd}}$ & 57 & 0.0705 & 12.9192 & 3.7523 \\
\hline $\begin{array}{l}\text { Non-dominated solution closest to the } \\
\text { barycenter obtained considering all solutions } \\
\text { on the approximate Pareto frontier. }\end{array}$ & $\mathrm{B}_{\text {all }}$ & 58 & 0.0553 & 13.0616 & 3.8427 \\
\hline $\begin{array}{l}\text { Non-dominated solution closest to the } \\
\text { utopian solution. }\end{array}$ & $\mathrm{U}_{\mathrm{t}}$ & 67 & 0.0738 & 8.3236 & 2.4376 \\
\hline
\end{tabular}


or utopian approach, are less dissimilar, but still provide a lot of information on alternative design solutions. Confirming what was observed previously for the two dimensional test example (De Sousa et al., 2013), it is noteworthy how the layout tool can provide potentially significant design gains. For example, in the present $3 \mathrm{D}$ application with three objective functions, a $38 \%$ reduction on the value of objective function $\mathrm{f}_{3}$ is obtained if solution $\mathrm{Ut}$ is chosen instead of solution $\mathrm{F}_{1}$. In a real design application this would mean a significant reduction on the cabling connecting the equipment, which can lead, for example, to cost savings and mitigation of integration problems.

The processing time spent for running each optimization was approximately 3 hours and 32 minutes, in a PC with a Core i5 CPU, $2.5 \mathrm{GHz}$ of clock and $4 \mathrm{~GB}$ of RAM memory.

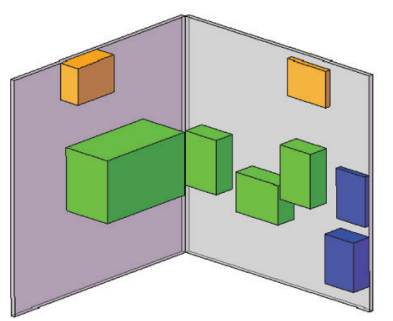

Best solution for center of mass (F1).

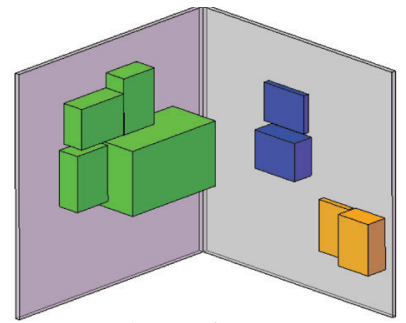

Best solution for equipment common set distance (F3)

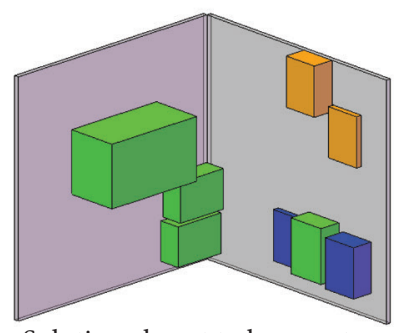

Solution closest to barycenter considering all solutions (Ball)

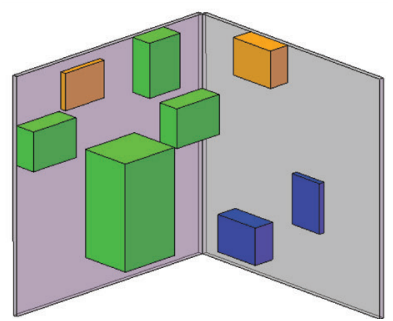

Best solution for heat density (F2).

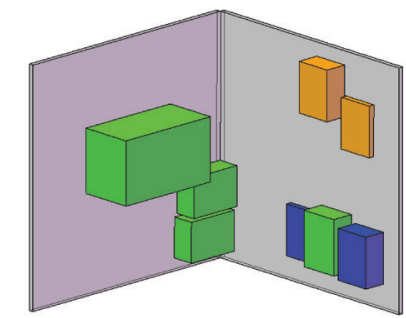

Solution closest to barycenter onsidering extreme solutions (Bnd)

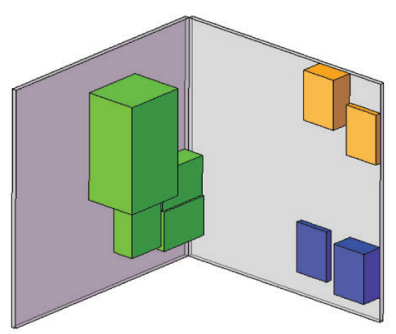

Solution closest to utopian solution (Ut).

Figure 13. Optimization with Three Objective Functions - Layout configurations for selected solutions. 


\section{CONCLUSIONS}

In this paper a tool for three dimensional multidisciplinary design conception of spacecraft equipment layout was presented. It is an evolution of an early prototype with $2 \mathrm{D}$ capability, which main features where presented in COBEM 2013 (De Sousa et al., 2013). The tool can be used either as a research bed for testing different candidate methodologies and optimization algorithms to the problem, as well as an operational tool to be used by an engineering design team. The choice of using Excel ${ }^{\circledR}$ as the main software platform over which the optimization tool is built, was based on the convenience of having a readily available and broadly known software, which could be easily used for data input, numerical calculations, output of results and integrator of CAD or CAE software.

The tool uses Cuco's multiobjective methodology (Cuco, 2011; Cuco et al., 2014) as the main framework for the layout optimization, which is performed by a customized implementation of the M-GEO (Galski, 2006) algorithm. The search for the optimal solutions, the approximate Pareto set, is performed from an initial completely random layout configuration. The user can select up to 5 different objective functions to guide the search. The user can also set which spacecraft panel's faces are available for positioning a given set of equipment. Excel ${ }^{\circledR}$ was coupled to SolidWorks ${ }^{\circledR}$, which is used to calculate design parameters and as a graphical interface, where candidate layout configurations can be visualized. Results are automatically retrieved to a dedicated Excel $^{\circledR}$ worksheet, becoming available to be further analyzed, either graphically or using internal Excel ${ }^{\circledR}$ features. The tool also embodies an automatic decision making procedure to select solutions on the approximate Pareto frontier, which, for a frontier with many non-dominated solutions, may help the user to decide which of them are more suitable to be further investigated. All these characteristics were exercised in a simplified three dimensional application example, which highlighted the potential benefits such a tool can provide.

The Excel ${ }^{\circledR}$ based spacecraft equipment layout tool presented in this paper can be considered the first "operational" version of a tool which preliminary results were presented at COBEM 2013 (De Sousa et al., 2013). It was conceived to be continuously improved with new features, and short term goals in its development are the inclusion of new optimization algorithms and new objective functions to address additional engineering issues, as well as its application to a full real spacecraft layout problem. This would imply in a much larger design problem. For instance, for the service module of a middle size satellite of $500 \mathrm{~kg}$, such as the MMP (Multi-Mission Platform) developed currently at INPE, the software would have to deal with around 88 design variables (for example, 22 equipment each one with four design variables). Moreover, there may be an increase in the number of constraints, depending on requirements posed on the positioning of some equipment.

\section{REFERENCES}

Baier, H. and Pühlhofer, T., 2003, "Approaches for further rationalization in mechanical architecture and structural design of satellites", In Proceedings of 54th International Astronautical Congress, Bremen, Germany.

Cuco, A.P.C., 2011, "Development of a Multiobjective methodology for layout optimization of equipment in artificial satellites" (in Portuguese), Master dissertation, Postgraduate Course in Space Technology and Engineering, National Institute for Space Research (INPE).

Cuco, A.P.C, De Sousa, F.L. and Silva Neto, A.J., 2014, "A multiobjective methodology for spacecraft equipment layouts", Optimization and Engineering. doi:10.1007/s11081-014-9252.

De Sousa, F.L., Muraoka, I. and Galski, R.L., 2007, "On the optimal positioning of electronic equipment in space platforms", In Proceedings of the 19th International Congress of Mechanical Engineering, Brasilia, Brasil.

De Sousa, F.L., 2002, “Otimização extrema generalizada: um novo algoritmo estocástico para o projeto ótimo", (INPE-9564-TDI/836), Ph.D. Thesis in Computação Aplicada, Instituto Nacional de Pesquisas Espaciais, 142p.
De Sousa, F.L., Ramos, F.M., Paglione, P. and Girardi, R.M., 2003, "New stochastic algorithm for design optimization", AIAA Journal, Vol. 41, No. 9, pp. 1808-1818.

De Sousa, F.L. and Takahashi, W.K., 2005, "Generalized Extremal Optimization Applied to Three-Dimensional Truss Design”, Proceedings of the $18^{\text {th }}$ International Congress of Mechanical Engineering (COBEM2O05), CDROM, Ouro Preto, Brasil.

De Sousa, F.L., Galski, R.L., Rocco, E.M., Becceneri, J.C., Santos, W.A. and Sandri, S.A., 2013, "A toll for multidisciplinary design conception of spacecraft equipment layout", $22^{\text {nd }}$ International Congress of Mechanical Engineering (COBEM, 2013), Ribeirão Preto, SP, Brazil.

Deb, K., Agrawal, S., Pratap, A. and Meyarivan, T., 2000, "A Fast Elitist Nondominated Sorting Genetic Algorithm for multi-objective optimization: NSGA-II". In: International Conference on Parallel Problem Solving From Nature, 6., Paris, France. Proceedings... Paris, France: Springer, pp. 849-858. 
Galski, R. L., 2006, "Desenvolvimento de versões aprimoradas híbridas, paralela e multiobjetivo do método da otimização extrema generalizada e sua aplicação no projeto de sistemas espaciais", (INPE-14795-TDI/1238), Ph.D. Thesis in Computação Aplicada, Instituto Nacional de Pesquisas Espaciais, São José dos Campos, Brazil, 279p.

Hengeveld, D.W., Braun, J.E., Eckhard, A.G. and Williams, A.D., 2011, "Optimal placement of electronic components to mininize heat flux nonuniformities", Journal of Spacecraft and Rockets, Vol. 48, No. 4, pp. 556-563. doi: 10.2514/1.47507.

Jackson, B. and Norgard, J., 2002, "A stochastic optimization for determining spacecraft avionics box placement", IEEE Aerospace Conference, Vol. 5, pp. 2373-2382.

Ferebee Jr., M.J. and Powers, R.B., 1987 "Optimization of payload mass placement in a dual keel space station", NASA Technical Memorandum 89051, March.

Ferebee Jr. M.J. and Allen C.L., 1991. "Optimization of payload placement on arbitrary spacecraft", Journal of Spacecraft and Rockets, Vol. 28, No. 5, pp. 612-614. doi: 10.2514/3.26288.

Mainenti-Lopes, I., De Sousa, F.L. and Souza, L.C.G., 2008, "The Generalized Extremal Optimization With Real Codification". Proceedings of International Conference on Engineering Optimization - EngOpt2008, Rio de Janeiro, pp. 01-05.

Mainenti-Lopes, I, Souza, L.C.G. and De Sousa, F.L., 2012, "Design of a nonlinear controller for a rigid-flexible satellite using multiobjective Generalized Extremal Optimization with real codification", Shock and Vibration, Vol. 19, No. 5, pp. 947-956. doi: 10.3233/ SAV-2012-0702.

Mainenti-Lopes, I., 2013, "A Multiobjective Approach to the Optimization of Solar Sail Trajectories" (In Portuguese), Ph.D. Thesis, Pós-graduação em Engenharia e Tecnologia Espaciais, área Mecânica Espacial e Controle, INPE.
Pühlhofer, T., Langer, H., Baier, H. and Huber, M., 2004, "Multicriteria and discrete configuration and design optimization with applications for satellites", In Proceedings of $10^{\text {th }}$ AIAA/ISSMO Multidisciplinary Analysis and Optimization Conference, Albany.

Rocco, E.M., Souza, M.L.O. and Prado, A.F.B.A., 2003, "MultiObjective Optimization Applied to Satellite Constellations I: Formulation of the Smallest Loss Criterion", Proceedings of the 54st International Astronautical Congress (IAC'O3), Bremen, Germany.

Rocco, E.M., Souza, M.L.O. and Prado, A.F.B.A., 2013, "Station Keeping of Costellations Using Multiobjective Strategies", Mathematical Problems in Engineering, Hindawi Publishing Corporation, Vol. 2013, pp. 15. doi:10.1155/2013/476451.

Sun, Z-G and Teng, H-F., 2003, "Optimal layout design of a satellite module”, Engineering Optimization, Vol. 35, No. 5, pp. 513-529.

Teng, H-F, Sun, S-L, Liu, D-Q and Li, Y-Z., 2001, "Layout optimization for the objects located within a rotating vessel - a three-dimensional packing problem with behavioral constraints", Computers and Operations Research, Vol. 28, pp. 521-535.

Teng, H-F., Chen, Y., Zeng, W., Shi, Y-J. and Hu, Q-H., 2010, "A Dualsystem variable grain cooperative coevolutionary algorithm: satellitemodule layout design", IEEE Transactions on Evolutionary Computation, Vol. 14, No. 3, pp. 438-455.

Vanderplaats, G., 2007, "Multidiscipline Design Optimization", Vanderplaats Research and Development Inc. ISBN 0-944956-04-1.

Venditti, F.C.F., Rocco, E.M., Prado, A.F.B.A. and Suhkanov, A., 2010, "Gravity-assisted maneuvers applied in the multi-objective optimization of interplanetary trajectories", Acta Astronautica, Elsevier Ltd., Vol. 67, No. 9-10, pp. 1255-1271. doi.:10.1016/j. actaastro.2010.06.022.

Zhang B., Teng H-F. and Shi Y-J., 2008, "Layout optimization of satellite module using soft computing techniques", Applied Soft Computing, Vol. 8, pp. 507-521. 